\title{
A Note on a New Form of Weak Continuous Multifunction
}

\author{
${ }^{1}$ N.Durga Devi, ${ }^{2}$ R. Raja Rajeswari, ${ }^{3}$ P. Thangavelu .
}

\begin{abstract}
The aim of this paper is to introduce the study of ultra - upper and lower-slightly continuous ultra multifunctions.
\end{abstract}

\section{Introduction and Preliminaries}

The concept of bitopological spaces was introduced by Kelly [2] in the year 1963. When all the works in bitopological spaces were depending on pair-wise concept, the definition of $(1,2) \alpha$-open sets introduced by Thivagar [3], in the year 1991,opened a new era of research in bitopology. He also defined $(1,2) \alpha$-continuous function and its weaker and stronger forms between two bitopological spaces. Continuity and multifunctions are two basic properties in general topology and set valued analysis. By multifunctions, we mean amapping from a point to a set. In the year 1978, Popa [7] introduced upper and lower weakly continuous functions and studied their properties. This concept of multifunctions was extended to bitopological spaces by defining ultra- multifunctions [5].

The main purpose of this article is to define and to generalize the ultra-upper and ultra-lower slightly continuous ultra- multifunctions in bitopological spaces. Throughout this paper, $\mathrm{X}$ means $(\mathrm{X}, \tau)$, where $\mathrm{X}$ is a non empty set and $\tau$ is the topology defined on it. By $\mathrm{Y}$, we mean the bitopological space $\left(\mathrm{Y}, \sigma_{1}, \sigma_{2}\right)$, where $\mathrm{Y}$ is a non empty set with two topologies $\sigma_{1}$ and $\sigma_{2}$ defined on it. 2000 Math. Subject Classification: 54C10, 54C08.

Keywords and Phrases: ultra-externally- disconnected,ultra-upper slightly continuous and ultra-lower slightly continuous multifunctions.

Definition 1.1. Let A be a subset of a bitopological space $\left(\mathrm{Y}, \sigma_{1}, \sigma_{2}\right)$. Then A is said to be [3] (i) $\sigma_{1} \sigma_{2}$-open if $A \in$ $\sigma_{1} \cup \sigma_{2}$, (ii) $\sigma_{1} \sigma_{2}$-closed if $A^{c} \in \sigma_{1} \cup \sigma_{2}$, (iii) $(1,2) \alpha$-open or ultra-open if $\mathrm{A} \subseteq \sigma_{1}-\operatorname{Int}\left(\sigma_{1} \sigma_{2}-\mathrm{Cl}\left(\sigma_{1}-\operatorname{Int}(\mathrm{A})\right)\right)$, where $\sigma_{1}-\operatorname{Int}(\mathrm{A})$ is the interior of A with respect to the topology $\sigma_{1}$ and $\quad \sigma_{1} \sigma_{2}-\mathrm{Cl}(\mathrm{A})$ is the intersection of all $\sigma_{1} \sigma_{2}$-closed sets containing A. Also A is said to be $(1,2) \alpha$-closed iff $A^{c}$ is $(1,2) \alpha$-open. (iv) $\operatorname{Int}_{(1,2) \alpha}(A)$ is the union of all $(1,2) \alpha$-open sets contained in A. The set of all $(1,2) \alpha$-open sets are denoted as $(1,2) \alpha O(X)$ and if this set forms a topology, then $\mathrm{X}$ is called as an ultra space.

Definition 1.2. An ultra multifunction $[5] \mathrm{F}_{\mathrm{u}}:(\mathrm{X}, \tau) \rightarrow\left(\mathrm{Y}, \sigma_{1}, \sigma_{2}\right)$ is a point to a set correspondence and is assumed that $F_{u}(x)=\varphi$ for all $x \in X$. Definition 1.3. The image set $U \subset X$ of the multifunction $F_{u}: X \rightarrow Y$ is defined [ 5 ] by $F_{u}(U)=U\left\{F_{u}(x) / x \in U\right\}$. Definition 1.4. For an ultra multifunction $F_{u}$, the upper and lower inverse [3] of $\mathrm{F}_{\mathrm{u}}$ is defined for any set $\mathrm{V} \subseteq \mathrm{Y}$, as $\mathrm{F}_{\mathrm{u}}{ }^{+}(\mathrm{V})=\left\{\mathrm{x} \in \mathrm{X} / \mathrm{F}_{\mathrm{u}}(\mathrm{x}) \subseteq \mathrm{V}\right\}$ and $\mathrm{F}_{\mathrm{u}}{ }^{-}(\mathrm{V})=\left\{\mathrm{x} \in \mathrm{X} / \mathrm{F}_{\mathrm{u}}(\mathrm{x}) \cap \mathrm{V}=\varphi\right\}$. Lemma 1.5. For any ultra multifunction $\mathrm{F}_{\mathrm{u}+}(\mathrm{V}) \subseteq \mathrm{F}_{\mathrm{u}-}(\mathrm{V})$. This result is proved in [5].

2. Ultra-Upper(Lower)-Slightly Continuous FunctionsDefinition 2.1. An ultra multifunction $\mathrm{F}_{\mathrm{u}}: \mathrm{X} \rightarrow \mathrm{Y}$ is said to be ultra-upper- slightly continuous if for each $\mathrm{x} \in \mathrm{X}$ and each (1, 2) $\alpha$-clopen set $V$ of $Y$ containing $F_{u}(x)$, there exists an open set $U$ of $X$ containing $x$ such that $F_{u}(U) \subset V$.Definition 2.2. An ultra multifunction $F_{u}: X \rightarrow Y$ is said to be ultra-lower-slightly continuous if for each $x \in X$ and each $(1$, 2) $\alpha$-clopen set $V$ of $Y$ such that $F_{u}(x) \cap V=\varphi$, there exists an open set $U$ of $X$ containing $x$ such that $F_{u}(x) \cap V=\varphi$ for all $\mathrm{x} \in \mathrm{U}$. 3

Example 2.3. Let $X=\{1,2,3\}$ with the topology $\tau=\{\varphi,, X,\{1,2\}\}$ and $Y=\{a, b, c, d\}$ with two topologies $\sigma_{1}$ $=\{\varphi, \mathrm{Y},\{\mathrm{a}\},\{\mathrm{b}\},\{\mathrm{a}, \mathrm{b}\},\{\mathrm{b}, \mathrm{c}, \mathrm{d}\},\{\mathrm{a}, \mathrm{c}, \mathrm{d}\},\{\mathrm{c}, \mathrm{d}\}\}$ and $\sigma_{2}=\{\varphi, \mathrm{Y},\{\mathrm{a}, \mathrm{c}, \mathrm{d}\}\}$. Define $\mathrm{F}_{\mathrm{u}}: \mathrm{X} \rightarrow \mathrm{Y}$ as $\mathrm{F}_{\mathrm{u}}(1)=\{\mathrm{a}\}, \mathrm{F}_{\mathrm{u}}$ $(2)=\{c\}, F_{u}(3)=\{a, d, c\}$. Here $F_{u}$ is ultra-upper-slightly continuous and ultra-lower-slightly continuous. Definition 2.4. A topological space $\left(Y, \sigma_{1} \sigma_{2}\right)$ is said to be ultra-externally-disconnected (U.E.D) if the $(1,2) \alpha$-closure of each $(1,2) \alpha$-open set of $Y$ is $(1,2) \alpha$ - open. 3. Comparisions Remark 3.1. Every ultra - slightly Continuous multifunctions is ultra almost continuous and ultra weakly contionuous multifunctions. Example 3.2. Let $X=\{1,2,3\}$ with the topology $\tau=\{\varphi, \mathrm{X},\{1,2\}\}$ and $\mathrm{Y}=\{\mathrm{a}, \mathrm{b}, \mathrm{c}, \mathrm{d}\}$ with two topologies $\sigma_{1}=\{\varphi, \mathrm{Y},\{\mathrm{a}, \mathrm{b}\},\{\mathrm{c}, \mathrm{d}\}\}$ and $\sigma_{2}=\{\varphi, \mathrm{Y}\}$.Define $\mathrm{F}_{\mathrm{u}}: \mathrm{X} \rightarrow \mathrm{Y}$ as $\mathrm{F}_{\mathrm{u}}(1)=\{\mathrm{a}, \mathrm{b}\}, \mathrm{F}_{\mathrm{u}}(2)=\{\mathrm{b}\}, \mathrm{F}_{\mathrm{u}}(3)=\{\mathrm{a}\}$. It is ultra-slightly continuous, ultra almost continuous and ultra weakly contionuous multifunc-tions. Example 3.3. The following example shows that the converse need not be true. Let $X=\{1,2,3\}$ with the topology $\tau=\{\varphi, X,\{1\}\}$ and $Y=\{a, b, c\}$ with two topologies $\sigma_{1}=\{\varphi, Y,\{a\}\}$ and $\sigma_{2}=\{\varphi, Y,\{a\},\{b, c\}\}$.Define $F_{u}: X \rightarrow Y$ as $F_{u}(1)=\{a\}, F_{u}(2)=\{a, c\}, F_{u}(3)=\{a, b\}$. It is ultra weakly contionuous but not ultra-slightly continuous multifunctionsExample 3.4. Let $X=\{1,2,3\}$ with the topology $\tau=$ $\{\varphi, X,\{1,2\}\}$ and $\mathrm{Y}=\{\mathrm{a}, \mathrm{b}, \mathrm{c}, \mathrm{d}\}$ with two topologies $\sigma_{1}=\{\varphi, \mathrm{Y},\{\mathrm{d}\},\{\mathrm{a}, \mathrm{d}\},\{\mathrm{b}, \mathrm{d}\},\{\mathrm{a}, \mathrm{b}, \mathrm{d}\}\}$ and $\sigma_{2}=\{\varphi, Y,\{a\}\}$.Define $F_{u}: X \rightarrow Y$ as $F_{u}(1)=\{a\}, F_{u}(2)=\{b, d\}, F_{u}(3)=\{b, d, c\}$. It is ultra almost contionuous but not ultra-slightly continuous multifunctions. 


\section{Characterization Of Ultra-Slightly Multifunctions}

Theorem 4.1. For an ultra multifunction $\mathrm{F}_{\mathrm{u}}: \mathrm{X} \rightarrow \mathrm{Y}$, the following are equivalent.

(i) $F_{u}$ is ultra upper slightly continuous.

(ii) $\mathrm{F}_{\mathrm{u}}{ }^{+}(\mathrm{V})$ is open in $\mathrm{X}$ for every $(1,2) \alpha$-clopen set $\mathrm{V}$ of $\mathrm{Y}$.

(iii) $\mathrm{F}_{\mathrm{u}}-(\mathrm{V})$ is closed in $\mathrm{X}$ for every $(1,2) \alpha$-clopen set $\mathrm{V}$ of $\mathrm{Y}$.

Proof : (i) $\Rightarrow$ (ii) Let $\mathrm{V}$ be a $(1,2) \alpha$-clopen set of $\mathrm{Y}$ and $\mathrm{x} \in \mathrm{F}_{\mathrm{u}}{ }^{+}(\mathrm{V})$. $\operatorname{ThenF}_{\mathrm{u}}(\mathrm{x}) \in \mathrm{V}$ and so there exists an open set $\mathrm{U}$ of $\mathrm{X}$ containing $\mathrm{x}$ such that $\mathrm{F}_{\mathrm{u}}(\mathrm{U}) \subset \mathrm{V}$. Hence we have $\mathrm{x} \in \mathrm{U}^{\mathrm{a}} \subset \mathrm{F}_{\mathrm{u}}{ }^{+}(\mathrm{V})$. And so, $\mathrm{x} \in \mathrm{U} \subset \mathrm{Int}\left(\mathrm{F}_{\mathrm{u}}{ }^{+}(\mathrm{V})\right)$, which implies $\mathrm{F}_{\mathrm{u}}{ }^{+}(\mathrm{V}) \subset \operatorname{Int}\left(\mathrm{F}_{\mathrm{u}}{ }^{+}(\mathrm{V})\right)$. Hence the result.

(ii) $\Rightarrow$ (i) Let $\mathrm{x} \in \mathrm{X}$ and $\mathrm{V}$ be any $(1,2) \alpha$-clopen set of $\mathrm{Y}$ containing $\mathrm{F}_{\mathrm{u}}(\mathrm{x})$. Then $\mathrm{x} \in \mathrm{F}_{\mathrm{u}}{ }^{+}(\mathrm{V})$ and $\mathrm{F}_{\mathrm{u}}{ }^{+}(\mathrm{V})$ is open. So $\mathrm{x} \in \operatorname{Int}\left(\mathrm{F}_{\mathrm{u}}{ }^{+}(\mathrm{V})\right)$. Therefore thereexists an open set $\mathrm{U}$ of $\mathrm{X}$ containing $\mathrm{x}$ such that $\mathrm{x} \in \mathrm{U} \subset \mathrm{F}_{\mathrm{u}}{ }^{+}(\mathrm{V})$, whichimplies $\mathrm{F}(\mathrm{U}) \subset \mathrm{V}$. Hence $\mathrm{F}_{\mathrm{u}}$ is ultra-upper-slightly continuous.(ii) $\Rightarrow$ (iii) Let $\mathrm{K}$ be a $(1,2) \alpha$-clopen set of $\mathrm{Y}$. Then $\mathrm{Y}-\mathrm{K}$ is also a clopenset of $\mathrm{Y}$. Also X- $\mathrm{F}_{\mathrm{u}}^{-}(\mathrm{K})=\mathrm{F}_{\mathrm{u}}+(\mathrm{Y}-\mathrm{K})$. Then $\operatorname{Int}\left(\mathrm{F}_{\mathrm{u}}{ }^{+}(\mathrm{Y}-\mathrm{K})\right)=\mathrm{X}-\mathrm{Cl}\left(\mathrm{F}_{\mathrm{u}}^{-}(\mathrm{K})\right) \cdot \mathrm{SoF}_{\mathrm{u}}(\mathrm{K})$ is a closed set in $\mathrm{X}$.

(iii) $\Rightarrow$ (ii) The fact that $F_{u}(Y-V)=X-F_{u}{ }^{+}(V)$ gives the result.Theorem 4.2. For an ultra multifunction $F_{u}$ $: X \rightarrow Y$, the following areequivalent.(i) $F_{u}$ is ultra-lower-slightly continuous.(ii) $F_{u}{ }^{-}(V)$ is an open set of $X$ for every $(1,2) \alpha$-clopen set $\mathrm{V}$ of $\mathrm{Y}$.(iii) $\mathrm{F}_{\mathrm{u}}{ }^{+}(\mathrm{V})$ is a closed set of $\mathrm{X}$ for every $(1,2) \alpha$-clopen set $\mathrm{V}$ of $\mathrm{Y}$.

Proof: (i) $\Rightarrow$ (ii) Let $V$ be a $(1,2) \alpha$-clopen set of $Y$ and $x \in F_{u}{ }^{-}(V)$. Then $F_{u}(x) \subset V$. By the definition, there exists an open set $U$ of $X$ containing xsuch that $F_{u}(x) \cap V=\varphi$ for all $x \in U$. Therefore, $F_{u}(U) \subset V$ and $U \subset F_{u}$

(V).As $U$ is open, $x \in U \subset \operatorname{Int}\left(F_{u^{-}}{ }^{-}(V)\right)$. Hence $F_{u^{-}}(\mathrm{V}) \subset \operatorname{Int}\left(F_{u^{-}}(\mathrm{V})\right)$.A NOTE ON A NEW FORM OF WEAK CONTINUOUS MULTIFUNCTION 5(ii) $\Rightarrow$ (iii) Let $\mathrm{V}$ be a $(1,2) \alpha$-clopen set of $\mathrm{Y}$. Then Y-V is also a $(1,2) \alpha$-clopen set of $\mathrm{Y}$. Also $\mathrm{X}-\left(\mathrm{F}_{\mathrm{u}}{ }^{+}(\mathrm{V})\right)=\mathrm{F}_{\mathrm{u}}{ }^{-}(\mathrm{Y}-\mathrm{V})=\operatorname{Int}\left(\mathrm{F}_{\mathrm{u}}{ }^{-}(\mathrm{Y}-\mathrm{V})\right)=\mathrm{X}-\mathrm{Cl}$

$\left(\mathrm{F}_{\mathrm{u}}{ }^{+}(\mathrm{V})\right)$. Therefore $\mathrm{F}_{\mathrm{u}}{ }^{+}(\mathrm{V})=\mathrm{Cl}\left(\mathrm{F}_{\mathrm{u}}{ }^{+}(\mathrm{V})\right)$. (iii) $\Rightarrow$ (i) Let $\mathrm{x}$ be any point of $\mathrm{X}$ and $\mathrm{V}$ be any $(1,2) \alpha$-clopen set of $Y$ such that $F_{u}(x) \cap V=\varphi$. Therefore $x \in F_{u}^{-}(V)$ and $\left.X-F_{u}^{-}(V)=F_{u}{ }^{+}(Y-V)\right)$. By assumption $F_{u}+(Y-V)$ is closed implies $\mathrm{x} \in \mathrm{Cl}\left(\mathrm{F}_{\mathrm{u}}{ }^{+}(\mathrm{Y}-\mathrm{V})\right)$. Hence there exists an open set $\mathrm{U}$ of $\mathrm{X}$ containing $\mathrm{x}$ such that $U \cap \mathrm{F}_{\mathrm{u}}{ }^{+}(\mathrm{Y}-\mathrm{V})=\varphi$. That is $\mathrm{U} \cap \mathrm{X}-\mathrm{F}_{\mathrm{u}}(\mathrm{V})=\varphi$ and so, $\mathrm{U} \subset \mathrm{F} \mathrm{u}^{-}(\mathrm{V})$. Thus $\mathrm{F}_{\mathrm{u}}{ }^{-}(\mathrm{U}) \subset \mathrm{V}$ and we get that $\mathrm{F}_{\mathrm{u}}(\mathrm{x}) \cap \mathrm{V}=\varphi$ for all $\mathrm{x} \in \mathrm{U}$. Theorem 4.3. Let $\left(Y, \sigma_{1}, \sigma_{2}\right)$ be a U.E.D. For a multifunction $\mathrm{F}_{\mathrm{u}}: \mathrm{X} \rightarrow \mathrm{Y}$, the following are equivalent. (i) $\mathrm{F}_{\mathrm{u}}$ is ultra-upper-slightly continuous.(ii) $\mathrm{Cl}\left(\mathrm{F}_{\mathrm{u}}{ }^{-}(\mathrm{V})\right) \subset \mathrm{F}_{\mathrm{u}}{ }^{-}(\mathrm{Cl}(\mathrm{V}))$ for every $(1,2) \alpha$-open set $\mathrm{V}$ of $\mathrm{Y}$.

(iii) $\mathrm{F}_{\mathrm{u}}{ }^{+}(\operatorname{Int}(1,2) \alpha(\mathrm{C})) \subset \operatorname{Int}\left(\mathrm{F}_{\mathrm{u}}{ }^{+}(\mathrm{C})\right)$ for every $(1,2) \alpha$-closed set $\mathrm{C}$ of $\mathrm{Y}$.Proof : (i) $\Rightarrow$ (ii) Let $\mathrm{V}$ be a $(1,2) \alpha$ open set of $\mathrm{Y}$. Since $\mathrm{Y}$ is U.E.D, $\left.\mathrm{Cl}_{(1,2) \alpha}(\mathrm{V})\right)$ is a clopen set of $\mathrm{Y}$. By Theorem 5.2.1, $\mathrm{F}_{\mathrm{u}}(\mathrm{Cl}(1,2) \alpha(\mathrm{V}))$ is a closed set ofX. So, $\mathrm{F}_{\mathrm{u}}^{-}(\mathrm{Cl}(1,2) \alpha(\mathrm{V}))=\mathrm{Cl}\left(\mathrm{F}_{\mathbf{u}^{-}}(\mathrm{Cl}(1,2) \alpha(\mathrm{V}))\right)$. Again $\mathrm{Fu}(\mathrm{V}) \subset \mathrm{F}_{\mathrm{u}}(\mathrm{Cl}(1,2) \alpha(\mathrm{V}))$. Therefore, $\mathrm{Cl}\left(\mathrm{F}_{\mathrm{u}}\right.$

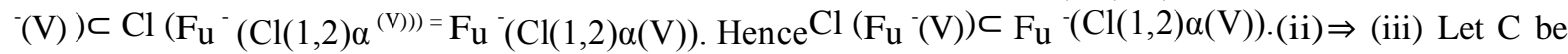
any $(1,2) \alpha$ - closed set of $Y$. Take $\mathrm{V}=\mathrm{Y}$-C, whichis $(1,2) \alpha$-open. Now $\mathrm{X}-\operatorname{Int}\left(\mathrm{F}_{\mathrm{u}}{ }^{+}(\mathrm{C})\right)=\mathrm{Cl}\left(\mathrm{X}-\mathrm{F}_{\mathrm{u}}{ }^{+}(\mathrm{C})\right)=$ $\mathrm{Cl}\left(\mathrm{F}_{\mathrm{u}}{ }^{-}(\mathrm{Y}-\mathrm{C})\right)=\mathrm{F}_{\mathrm{u}}{ }^{-}\left(\mathrm{Cl}_{(1,2) \alpha}(\mathrm{Y}-\mathrm{C})\right)$. Now, $\mathrm{X}-\operatorname{Int}\left(\mathrm{F}_{\mathrm{u}}{ }^{+}(\mathrm{C})\right) \subset \mathrm{F}_{\mathrm{u}}{ }^{-}(\mathrm{Cl}(1,2) \alpha(\mathrm{Y}-\mathrm{C}))=\mathrm{F}_{\mathrm{u}}{ }^{-}(\mathrm{Y}-\mathrm{Int}$

$(1,2) \alpha(C))=X-F_{u^{-}}{ }^{-}(\operatorname{Int}(1,2) \alpha(C))$. Hence we can say that $\mathrm{F}_{\mathrm{u}}{ }^{+}(\operatorname{Int}(1,2) \alpha(C)) \subset \operatorname{Int}\left(\mathrm{F}_{\mathrm{u}}{ }^{+}(\mathrm{C})\right)$.

(iii) $\Rightarrow$ (i) Let $\mathrm{x} \in \mathrm{X}$ and $\mathrm{V}$ be a $(1,2) \alpha$-open set containing $\mathrm{F}_{\mathrm{u}}(\mathrm{x})$. Then by (iii), we have $\mathrm{x} \in \mathrm{F}_{\mathrm{u}}{ }^{+}(\mathrm{V})=\mathrm{F}_{\mathrm{u}}$ ${ }^{+}(\operatorname{Int}(1,2) \alpha(\mathrm{V})) \subset \operatorname{Int}\left(\mathrm{F}_{\mathrm{u}}{ }^{+}(\mathrm{V})\right)$. Therefore there exists an open set $\mathrm{U}$ of $\mathrm{x}$ such that $\mathrm{x} \in \mathrm{U} \subset \mathrm{F}_{\mathrm{u}}{ }^{+}(\mathrm{V})$. Now, we have $F_{u}{ }^{-}(U) \subset V$ and hence $F_{u}$ is ultra-upper-slightly continuous.

6 Theorem 4.4. Let $\left(Y, \sigma_{1}, \sigma_{2}\right)$ be a U.E.D. For a multifunction $\mathrm{F}_{\mathrm{u}}: \mathrm{X} \rightarrow \mathrm{Y}$,

the following are equivalent.(i) $\mathrm{F}_{\mathrm{u}}$ is ultra-lower-slightly continuous.

(ii) $\mathrm{Cl}\left(\mathrm{F}_{\mathrm{u}}{ }^{+}(\mathrm{V})\right) \subset \mathrm{F}_{\mathrm{u}}{ }^{+}\left(\mathrm{Cl}_{(1,2) \alpha}(\mathrm{V})\right)$ for every $(1,2) \alpha$-open set $\mathrm{V}$ of $\mathrm{Y}$.(iii) $\mathrm{F}_{\mathrm{u}}{ }^{-}\left(\operatorname{Int}_{(1,2) \alpha}(\mathrm{C})\right) \in \operatorname{Int}\left(\mathrm{Fu}_{\mathrm{u}}{ }^{-}(\mathrm{C})\right) \quad$ for every $(1,2) \alpha$-closed set $\mathrm{C}$ of $\mathrm{Y}$ Proof : Similar to the Theorem 5.2.3.Definition 4.5. A bitopological space $\left(\mathrm{Y}, \sigma_{1}, \sigma_{2}\right)$ is called an ultra connected space [9] if there exists two disjoint non empty $(1,2) \alpha$-open sets $\mathrm{U}$ and $\mathrm{V}$ such that $\mathrm{Y}=\mathrm{U} \cap \mathrm{V}$. Theorem 4.6. Let $\mathrm{F}_{\mathrm{u}}: \mathrm{X} \rightarrow \mathrm{Y}$ be an ultra-upper-slightly continuous function. If $\mathrm{X}$ is a connected space, then $\mathrm{Y}$ is an ultra connected space. Proof : Suppose $\mathrm{Y}$ is not ultra connected. Then there exists two disjoint non empty $(1,2) \alpha$-open sets $\mathrm{U}$ and $\mathrm{V}$ such that $\mathrm{Y}=\mathrm{U} \cap \mathrm{V}$. Also $\mathrm{U}$ and $\mathrm{V}$ are $(1,2) \alpha$-clopen sets. Given $\mathrm{F}_{\mathrm{u}}$ is ultra-upper-slightly continuous. So $\mathrm{F}_{\mathrm{u}}{ }^{+}(\mathrm{U})$ and $\mathrm{F}_{\mathrm{u}}{ }^{+}(\mathrm{V})$ are $(1,2) \alpha$-open sets in $\mathrm{X}$. Now $\mathrm{F}_{\mathrm{u}}{ }^{+}(\mathrm{U})$ and $\mathrm{F}_{\mathrm{u}}{ }^{+}(\mathrm{V})$ are non emptyand disjoint and $\mathrm{X}=\mathrm{F}_{\mathrm{u}}{ }^{+}(\mathrm{U}) \cup \mathrm{F}_{\mathrm{u}}{ }^{+}(\mathrm{V})$. This proves that $\mathrm{X}$ is not connected. Acontradiction.

Theorem 4.7. Let $\mathrm{F}_{\mathrm{u}}: \mathrm{X} \rightarrow \mathrm{Y}$ be an ultra-upper-slightly continuous surjection. If $\mathrm{Y}$ is ultra normal and U.E.D then $\mathrm{X}$ is $\mathrm{T}_{2}$. Proof : Suppose $\mathrm{Y}$ is ultra normal. For any two distinct $(1,2) \alpha$-closed sets $\mathrm{H}$ and $\mathrm{K}$ there exists two (1, 2) $\alpha$-open sets $\mathrm{U}$ and $\mathrm{V}$ such that $\mathrm{H} \subset \mathrm{U}$ and $\mathrm{K} \subset \mathrm{V}$. $\mathrm{H} \subset \mathrm{Cl}_{(1,2) \alpha}(\mathrm{U})$ and $\mathrm{K} \subset \mathrm{Cl}_{(1,2 \alpha}(\mathrm{V})$. As $\mathrm{F}_{\mathrm{u}}$ is ra-upper-slightly continuous and $\mathrm{Y}$ is U.E.D. $\mathrm{F}_{\mathrm{u}}{ }^{+}(\mathrm{V})\left(\mathrm{Cl}(1,2) \alpha^{(\mathrm{U}))}\right.$ and $\mathrm{F}_{\mathrm{u}}{ }^{+}(\mathrm{Cl}(1,2) \alpha(\mathrm{V}))$ are open

in $\mathrm{X}$. Since $\mathrm{F}_{\mathrm{u}}$ is ultra-upper-slightly continuous, for $\mathrm{x} \in \mathrm{X}$ and for each $(1,2) \alpha$-clopen set say $\mathrm{Cl}_{(1,2) \alpha}$ (U) containing $\mathrm{F}_{\mathrm{u}}{ }^{+}(\mathrm{x})$, there exists an open set $\mathrm{G}$ of $\mathrm{X}$ containing $\mathrm{x}$ such that $\mathrm{F}_{\mathrm{u}}(\mathrm{G}) \subset \mathrm{Cl}_{(1,2) \alpha}(\mathrm{U})$. For $\mathrm{y} \in \mathrm{X}$, we get a $(1,2) \alpha$-clopen set $\mathrm{Cl}_{(1,2) a}(\mathrm{~V})$ containing $\mathrm{F}_{\mathrm{u}}{ }^{+}(\mathrm{y})$, there exists an open set $\mathrm{H}$ of $\mathrm{X}$ containing y such that $\mathrm{F}_{\mathrm{u}}(\mathrm{H}) \subset \mathrm{Cl}_{(1,2) a}(\mathrm{~V})$. Clearly $\mathrm{Cl}_{(1,2) \alpha}(\mathrm{U})$ and $\mathrm{Cl}_{(1,2) \alpha}(\mathrm{V})$ are disjoint and non empty. Hence $\mathrm{X}$ is $\mathrm{T}_{2 .} 7$ 


\section{Conclusion}

Topology, which until recently was a conglomeration of loosely related the-orems, become a systematic science and topological methods penetrated in to many other domain of sciences, like image processing, DNA structures etc. Since then several thousands of works have been dedicated to the investigation of bitopology , but a very few are with multi functions. It is to be noticed in a recent study the over expression of P-gycoprotein (Pgp) in breast and other cancer is thought to be largely involved in the development of multidrug resis-tance to chemotherapy. This Pgp has been reported to have multiple topology and multiple functions. Hence a research on multifunctions in bitopological spaces may definitely has its own place in medical science and also in other fields of sciences.

\section{References}

[1] M.C. Dutta ., Contribution to theory of bitopological spaces, Ph.D Thesis, Pilani, 1971.

[2] J.C.Kelli., Bitopological Spaces, Pro.London Math.Soc,13(1963),71-89.

[3] M.Lellis Thivagar., Generalization of $(1,2) \alpha$-continuous functions, Pure and Applied Mathematika Sciences 33 (1991),55-63.

[4] G.Navalagi, M.Lellis Thivagar and R.RajaRajeswari., (1, 2) $\alpha$ - Hyperconnected spaces, International Journal of Mathematics and Analysis, Vol.3 (2006), 120 -129.

[5] G.Navalagi, M.Leelis Thivagar and R.RajaRajeswari., On ultra multifunctios in bitopo-logical spaces, International Journal of Mathematics, Coputer Science and Information Technology Vol.1,No.1(2008),69-74.

[6] 6. V.Popa., A note on weakly and almost continuous multifunctions,Univ.u Novom sadu, Zb.Rad.Priorod. - Mat.Fak.Ser.Mat.21, 2(1991), 31-38.

[7] 7. V.Popa and T.Noiri., on upper and lower weakly- - continuous multifunctions,Novi.Sad.J.Math ,Vol.32, No.1 (2002), 7-24.

[8] 8. R.RajaRajeswari,Bitopological concepts of some separation properties, Ph.D Thesis, Madurai Kamaraj University, Madurai, India, 2009

[9] 9. M.S.Sarask, N.Gowrisankar and N.Rajesh., on upper and lower $\gamma$-continuous mul-tifunctions, Int.J.contemp.Math.Sciences, Vol.5 (2010), No.6, $281-288$. 